https://helda.helsinki.fi

\title{
Grand canonical Monte Carlo simulation on adsorption of aniline on the ice surface
}

\section{Fu, Zihao}

2019-09-15

Fu, Z, He , N , Zhou , P , Xie , H-B , Fu , Z , Liu , C \& Chen , J 2019, ' Grand canonical Monte Carlo simulation on adsorption of aniline on the ice surface ' , Journal of Molecular Liquids , vol. 290 , 111221 . https://doi.org/10.1016/j.molliq.2019.111221

http://hdl.handle.net/10138/331657

https://doi.org/10.1016/j.molliq.2019.111221

cc_by_nc_nd

acceptedVersion

Downloaded from Helda, University of Helsinki institutional repository.

This is an electronic reprint of the original article.

This reprint may differ from the original in pagination and typographic detail.

Please cite the original version. 


\section{Accepted Manuscript}

Grand canonical Monte Carlo simulation on adsorption of aniline on the ice surface

Zihao Fu, Ning He, Putian Zhou, Hong-Bin Xie, Zhiqiang Fu, Cong Liu, Jingwen Chen

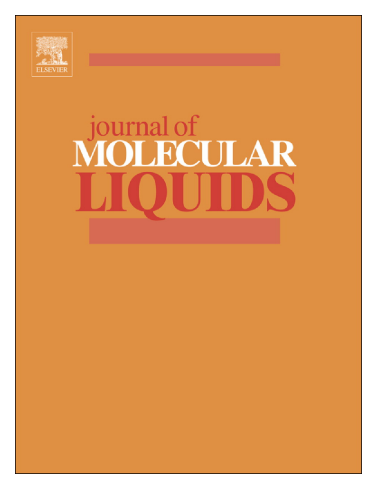

PII:

S0167-7322(18)35751-9

DOI: https://doi.org/10.1016/j.molliq.2019.111221

Article Number:

111221

Reference:

MOLLIQ 111221

To appear in:

Journal of Molecular Liquids

Received date:

7 November 2018

Revised date:

12 June 2019

Accepted date:

19 June 2019

Please cite this article as: Z. Fu, N. He, P. Zhou, et al., Grand canonical Monte Carlo simulation on adsorption of aniline on the ice surface, Journal of Molecular Liquids, https://doi.org/10.1016/j.molliq.2019.111221

This is a PDF file of an unedited manuscript that has been accepted for publication. As a service to our customers we are providing this early version of the manuscript. The manuscript will undergo copyediting, typesetting, and review of the resulting proof before it is published in its final form. Please note that during the production process errors may be discovered which could affect the content, and all legal disclaimers that apply to the journal pertain. 


\section{Grand Canonical Monte Carlo Simulation on Adsorption of}

\section{Aniline on the Ice Surface}

Zihao $\mathrm{Fu}^{\dagger}$, Ning $\mathrm{He}^{\ddagger}$, Putian Zhou ${ }^{\S}$, Hong-Bin Xie ${ }^{\dagger *}$, Zhiqiang $\mathrm{Fu}^{\dagger}$, Cong Liu ${ }^{\dagger}$, Jingwen Chen ${ }^{\dagger}$

${ }^{\dagger}$ Key Laboratory of Industrial Ecology and Environmental Engineering (Ministry of Education), School of Environmental Science and Technology, Dalian University of Technology, Dalian 116024, China

${ }^{\ddagger}$ State Key Laboratory of Fine Chemicals, Dalian University of Technology, Dalian 116024, China

${ }^{\S}$ Institute for Atmospheric and Earth System Research / Physics, Faculty of Science, University of Helsinki, P. O. Box 64, FIN-00014 Helsinki, Finland

ABSTRACT: Aniline has been found to have frequent environmental occurrence and high toxicity. However, little study has been performed on its environmental fate. Here, we employed Grand Canonical Monte Carlo simulations (GCMC) to investigate the adsorption behavior of aniline on hexagonal ice surface at $200 \mathrm{~K}$ using our modified force field of aniline and TIP5P force field of water. The results indicate that the adsorption isotherm of aniline exhibits a "monolayer saturation plateau", starting with a rapid increase, then a plateau, and finally a condensed phase. Under very low surface coverage, the adsorption isotherm apparently follows Langmuir type adsorption isotherm although anilines can be adsorbed to various sites. Within the range of the apparent Langmuir-type adsorption isotherm, adsorbed anilines are independent from each other and most anilines are almost parallel to the ice surface and form two $\mathrm{N}-\mathrm{H} \bullet \cdot \mathrm{O}$ hydrogen bonds. With the increase of coverage, the adsorbed anilines can interact with each other, resulting in the deviation from the apparent 
Langmuir-type adsorption isotherm. In addition, the adsorption energy from GCMC simulation $\left(-65.91 \mathrm{~kJ} \mathrm{~mol}^{-1}\right)$ is well consistent that from our validating quantum chemistry calculation $\left(-69.34 \mathrm{~kJ} \mathrm{~mol}^{-1}\right)$, further confirming the reliability of our GCMC simulation results.

Keywords: Adsorption; Monte Carlo simulation; Aniline; Ice Surface; Atmospheric chemistry.

\section{INTRODUCTION}

Ice particles are critically important environmental components in cirrus clouds, formed in the upper troposphere, and earth surface at high latitudes and high mountains.[1-3] They can effectively capture atmospheric pollutants through chemical or physical interactions.[1, 2, 4-9] These chemical/physical interactions on the air-ice interface can change the electronic structure characteristics of adsorbates and therefore modify their chemical activity, ultimately affecting the fate of pollutants from the atmosphere.[4, 6, 8-16] Therefore, it is necessary to investigate the adsorption of atmospheric pollutants on the ice surface for evaluating their environmental risk.

Atmospheric organic $\mathrm{NH}_{x}$-containing compounds $(x=1,2)$ are one kind of pollutants with potential environmental risk. Currently, about 160 organic $\mathrm{NH}_{x^{-}}$ containing compounds have been detected in the atmosphere.[17] Many studies have been performed to concern their atmospheric fate.[18-22] However, little study has been done on their adsorption on ice surface. In principle, organic $\mathrm{NH}_{x}$-containing compounds can form $\mathrm{N}-\mathrm{H} \bullet \bullet \mathrm{O}$ and $\mathrm{N} \bullet \bullet \mathrm{H}-\mathrm{O}$ hydrogen bonds with the ice surface, which can cause their adsorption on the ice surface in a similar way as the $\mathrm{O} \bullet \bullet \cdot \mathrm{H}-\mathrm{O}$ hydrogen bonds and $\mathrm{O}-\mathrm{H} \bullet \bullet \pi$ bonds driving the adsorption of benzaldehyde[23] and aromatic molecules,[24] respectively. As the first case for adsorption of these 
compounds on ice surface, Szentirmai et al[25] found that methylamine, the simplest $\mathrm{NH}_{x}$-containing compound, can be adsorbed effectively on the ice surface by the interplay of $\mathrm{N}-\mathrm{H} \bullet \bullet \mathrm{O}$ and $\mathrm{N} \bullet \bullet \mathrm{H}-\mathrm{O}$ hydrogen bonds between methylamine and surface water molecules as well as the dipolar interactions between neighboring adsorbed methylamines. Among detected atmospheric $\mathrm{NH}_{x}$-containing compounds, various functional groups are attached to the $-\mathrm{NH}_{x}$ group. The functional groups could interact with the ice surface themselves or affect the interactions between $-\mathrm{NH}_{x}$ group and the ice surface via changing the $\mathrm{N} \bullet \bullet \cdot \mathrm{H}-\mathrm{O}$ or $\mathrm{N}-\mathrm{H} \cdot \bullet \cdot \mathrm{O}$ hydrogen bonds strength, which lead various adsorption mechanisms of $\mathrm{NH}_{\mathrm{x}}$-containing compounds on the ice surface. Therefore, it is essential to investigate the adsorption of other $\mathrm{NH}_{x^{-}}$ containing compounds, especially those with unique structures, to further understand the adsorption of $\mathrm{NH}_{x}$-containing compounds on the ice surface.

Aniline (AN) is one kind of organic $\mathrm{NH}_{x}$-containing compounds. As an important intermediate or precursor for many industrial chemicals such as rubbers, polymers, dyes, pesticides, pharmaceuticals and explosives, it can be inevitably released into the environment in the process of its production, usage and transportation.[26-29] In addition, automobile vehicle exhaust is another main source for aniline since it is usually used as gasoline antiknock agents.[29] Aniline has been listed as a hazardous organic compound by the US Environmental Protection Agency[26] and a priority pollutant in China because of its high toxicity, chemical and biochemical stability.[29] The concentration of aniline was found to be up to tens of pptv in the urban atmosphere.[17, 30-32] However, it is surprising that little study has been performed to concern its fate in the environment although its toxicological effect and (potential) environmental occurrence.[26, 33, 34] In view of electronic structure, aniline includes two functional groups, phenyl and $-\mathrm{NH}_{2}$, which both can interact with the ice surface. 
The phenyl group can interact with the ice surface via $\mathrm{O}-\mathrm{H} \bullet \bullet \pi$ bonds, and $-\mathrm{NH}_{2}$ can interact with the ice surface as both a H-bond donor and acceptor. The various possible interactions between aniline and the ice surface make it difficult to guess which interactions drive adsorption of aniline on the ice surface. Therefore, in order to understand the atmospheric fate of aniline and extend current knowledge of adsorption of organic $\mathrm{NH}_{x}$-containing compounds on the ice surface, the information about the adsorption of aniline on the ice surface is crucial.

In this paper, we used Grand Canonical Monte Carlo (GCMC) simulations to investigate the adsorption behaviors of aniline on the surface of ice. As it is known, selecting reliable force fields is the key of the success for GCMC simulations. Here, TIP5P water model,[35] which can well describe the water interaction, was selected as force field of ice. For aniline, a modified force field based on OPLS-AA were used. Based on the simulation results, we calculated and analyzed the adsorption isotherm of aniline and probed the properties of the adsorbed aniline at diverse coverages in terms of the orientations of the aniline molecules, hydrogen bonding interactions and energetics of adsorption. The results are of significance for understanding the adsorption mechanism of aniline itself on the surface of ice, also other aromatics containing $\mathrm{NH}_{x}$ group.

\section{COMPUTATIONAL DETAILS}

2.1 Ice surface model and GCMC simulation. The adsorption of aniline on the ice surface has been investigated by performing a series of GCMC simulations at the tropospheric temperature $T=200 \mathrm{~K}$. Here, we chose the 0001 surface of a perfect hexagonal ice $\left(\mathrm{I}_{h}\right)$ as the ice surface model. The 0001 surface of a perfect $\mathrm{I}_{h}$ ice is considered to well simulate the actual surface of atmospheric ice[36-38] and has been successfully used to investigate the adsorption of (semi)volatile organic compounds 
((S)VOCs) on the ice surface.[9, 23-25, 39-46] The setup of simulation box was the same as that in our recent study on the adsorption of nitrobenzene on the ice surface.[39] Specifically, the simulation box was rectangular, with the $X, Y$, and $\mathrm{Z}$ edges being 100, 35.926, and $38.891 \AA$. The ice phase consisted of 18 molecular layers of proton disordered $\mathrm{I}_{h}$ ice, a total of 2880 water molecules arranged along $X$ axis (the surface normal) in the middle of the basic box with 3D periodic boundary conditions. To obtain the adsorption isotherm of aniline, 29 independent GCMC simulations were performed. The chemical potential $(\mu)$ of aniline for a given GCMC simulation varied from -65.04 to $-56.56 \mathrm{~kJ} \mathrm{~mol}^{-1}$, which covers the cases of adsorption from those with no adsorbed aniline molecules to those with the basic box all filled. The adsorption isotherm was directly calculated by the average number of adsorbed aniline molecules $\langle N\rangle$ as a function of $\mu$ values.

The GCMC simulations were performed with the MMC program developed by Mezei.[47-49] The five-site TIP5P potential model[35] and our modified OPLS-AA force field (detailed in the following section) were used to simulate water molecules of ice phase and aniline, respectively. Although the TIP5P water model does not perfectly simulate all behaviors of aqueous phases at low temperature, $[50,51]$ the TIP5P model is considered to be one of the good water models with better performance for predicting the melting point of $\mathrm{I}_{h}$ ice $[35,51,52]$ and the experimental liquid-liquid phase transitions than other models.[53] More importantly, previous studies found that the adsorption for methanol,[15] formic acid,[54] benzaldehyde,[23] acetaldehyde[55] on ice surface with TIP5P model can well agree with the experimental observation. Water and aniline molecules were rigid in the simulation system. The employed geometry of aniline was listed in the support information (SI). The interaction of the molecule pair was computed as the sum of 
Coulomb electrostatic and Lennard-Jones (LJ) interactions between all pairs of their interaction sites. Here, we did not consider the long-range correction of the electrostatic interaction since it was found to have a negligible effect on the adsorption isotherm for the systems similar to ours.[56, 57] The total potential energies of the simulation systems were computed as the sum of the interaction energy of every molecular pair within a center-center cutoff distance of $12.5 \AA$. In the GCMC simulation, the insertion/remove and particle displacement steps are performed in an alternating manner. In an insertion/remove step, the aniline molecules are inserted into or removed from the simulation box with the same possibility using the cavity biased algorithm of Mezei.[48, 49] For the particle displacement, randomly selected water or aniline molecule moves no more than $0.25 \AA$ and rotates no more than $15^{\circ}$ around a randomly selected coordinate axis. We have to mention that the insertion was only attempted to enter the cavity with a radius of at least $2.9 \AA$. In principle, the choice of cavity radius can only affect the sampling efficiency, not the final result. In addition, we noted that with the same cavity radius, calculated adsorption isotherm of benzaldehyde[23] on ice surface at relative short simulation time is well consistent with experimental one. Since the molecular size of aniline is similar to that of benzaldehyde, the selection of cavity radius for the insertion attempts of aniline should be reasonable. Totally, $6 \times 10^{8}$ Monte Carlo simulation steps were performed in each GCMC simulation. The first $4 \times 10^{8}$ steps are taken as an equilibrium run, the other $2 \times 10^{8}$ steps as a production run. During the production run, one configuration was saved for every $10^{5}$ GCMC steps (totally 2000 sample configurations) for further analysis at selected $\mu$ values.

2.2 Force field parameter modification for aniline. Similar to our recent study on the adsorption of nitrobenzene on ice surface,[39] the scheme "changing atomic 
charges and keeping LJ parameters" has been applied to determine appropriate aniline force field.[58, 59] Here, the LJ parameters of aniline come from the OPLS-AA force field.[60] The choice of partial charges for a new molecule is challenging. The stateto-art technology is still to fit the simulation results with adjusting initial charges to the experimental ones for some physical quantities, e.g. the partial charges of aniline in the original OPLS force field was determined by arbitrarily adjusting initial charges to fit experimental quantity.[60] Herein, the criterion for selecting the atomic charges of aniline is that the simulations with adjusted atomic charges and TIP5P water force field can repeat the experimental hydration free energy at $T=298.15 \mathrm{~K}$, a widely used scheme for determining the atomic charges of small molecules for the simulation in the aqueous phase.[58, 59, 61] The atomic charges of aniline were adjusted by multiplying its initial charges by a scaling factor. In principle, the initial charges for the adjustment can come from empirical and physical values (e.g. initial charges of aniline was obtained by a simple combination of the charge parameters of benzene and methylamine[60]) and quantum chemistry calculations in gaseous phase.[62, 63] The charges of aniline from natural bond orbital (NBO) analysis at the B3LYP/631G(d) level within Gaussian09 program[64] were taken as its initial values for the force field modification. It deserves mentioning that the RESP charge of nitrobenzene was taken as its initial values for the force field modification of nitrobenzene in our recent study.[39] However, the calculated RESP charge for $-\mathrm{NH}_{2}$ of aniline is -0.185 $e$. As an electron-donating group, it could be too negative.

The potential of mean force (PMF) calculation for the aniline transfer through water liquid phase was employed to obtain the hydration free energy $\left(\Delta G^{*}\right)$ of aniline. PMF calculation utilizing the umbrella sampling technology was performed in GROMACS 4.5.5 package.[65] The details for PMF calculation setup are similar to 
our recent study on the adsorption of nitrobenzene on ice surface and were presented in SI.[39]

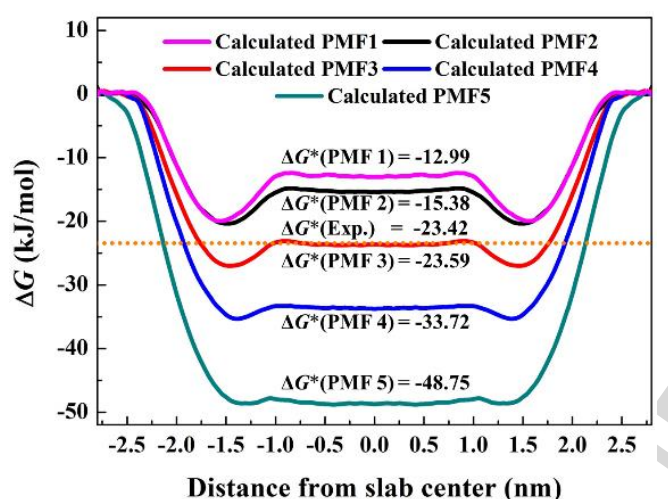

Fig. 1. PMF (potential of mean force) profiles for moving aniline through a water slab with different charge parameters. "PMF 1" represents the PMF of aniline with the original OPLS-AA charges, "PMF 2", "PMF 3", "PMF 4" and "PMF 5" represent the PMF of aniline with NBO charges $\times$ scaling factor, $0.7,0.8,0.9$ and 1.0 , respectively. The orange dotted line presents the benchmark hydration free energy derived from three experimental Henry's law constants.

\section{RESULTS AND DISCUSSION}

\subsection{Force field parameters modification for aniline}

The free energy profiles for one aniline molecule across the water slab are presented in Fig. 1. With three different experimental Henry's law constants $(5.2,6.0$ and $\left.4.6 \mathrm{~mol} \mathrm{~cm}^{-3} \mathrm{~Pa}^{-1}\right)$ at $298 \mathrm{~K},[66,67]$ the $\Delta G^{*}$ values were calculated to be -23.40 , -23.76 and $-23.10 \mathrm{~kJ} \mathrm{~mol}^{-1}$, respectively, according to eq. S2 (SI). Their average value was shown in the orange dotted line in Fig. 1 . The $\Delta G^{*}$ value, predicted by the force field of aniline containing NBO charges $\times 0.80$ and OPLS-AA LJ parameters (see PMF 3 in Fig. 1), is well consistent with the experimental average value. Other aniline force fields either underestimate or overestimate the $\Delta G^{*}$ values. Therefore, our modified force field for aniline consists of OPLS-AA LJ parameters and NBO charges $\times 0.80$, detailed in Table 1 . 
Table 1. Modified force field parameter of aniline and atomic charges of aniline from original OPLS-AA force field

\begin{tabular}{lccccc} 
molecule & atom & $\sigma(\mathrm{nm})$ & $\begin{array}{c}\varepsilon(\mathrm{kcal} \\
\left.\mathrm{mol}^{-1}\right)\end{array}$ & $\begin{array}{c}\text { OPLS-AA } \\
q(e)\end{array}$ & $\begin{array}{c}\mathrm{NBO} \times 0.80 \\
q(e)\end{array}$ \\
\hline $\mathrm{H}_{\mathrm{s}}$ & $\mathrm{C}_{\text {ipso }}$ & 0.355 & 0.070 & 0.100 & 0.133 \\
$\mathrm{C}_{\text {ortho }}$ & 0.355 & 0.070 & -0.115 & -0.226 \\
$\mathrm{C}_{\text {meta }}$ & 0.355 & 0.070 & -0.115 & -0.173 \\
$\mathrm{C}_{\mathrm{S}}$ & $\mathrm{C}_{\text {para }}$ & 0.355 & 0.070 & -0.115 & -0.218 \\
$\mathrm{C}_{\text {ortho }}$ & $\mathrm{H}_{\text {ortho }}$ & 0.242 & 0.030 & 0.115 & 0.182 \\
$\mathrm{C}_{\mathbf{H}_{\text {para }}}$ & $\mathrm{H}_{\text {meta }}$ & 0.242 & 0.030 & 0.115 & 0.187 \\
& $\mathrm{H}_{\text {para }}$ & 0.242 & 0.030 & 0.115 & 0.186 \\
& $\mathrm{~N}_{\mathrm{S}}$ & 0.325 & 0.170 & -0.900 & -0.667 \\
& $\mathrm{H}_{\mathrm{S}}$ & 0.000 & 0.000 & 0.400 & 0.313 \\
\hline
\end{tabular}

To further verify the modified aniline force field, we compared some experimental physical properties of aniline with corresponding values calculated by our modified force field. Here, the dipole moment, density, evaporation enthalpy and heat capacity of aniline that are relevant to the intermolecular interaction among aniline molecules (see SI for computational details) were selected as target physical properties for the comparison. Due to the shortage of experimental physical properties at $200 \mathrm{~K}$, the same temperature as that of GCMC simulation, the comparison for the temperature-dependent physical properties such as density, evaporation enthalpy and heat capacity of aniline was made at $298.15 \mathrm{~K}$. Hopefully, the conclusion for such verification at $298.15 \mathrm{~K}$ can still work at $200 \mathrm{~K}$. The computed dipole moment, density, evaporation enthalpy and heat capacity of aniline with modified force field and corresponding experimental values and literature values[60] with original OPLSAA force field are presented in Table 2. As can be seen in Table 2, the computed evaporation enthalpy and density from the simulation based on the original OPLS-AA 
force field are closer to experimental values than those based on modified force field. However, the calculated dipole moment and heat capacity based on our modified force filed are closer to the experimental value than those from the original OPLS-AA force field. On the whole, the calculated density, evaporation enthalpy, heat capacity and dipole moment with our modified force field are generally comparable to the experimental ones and within an acceptable error of around 5\%. In addition, the structural parameters from modified OPLS force field including bond length and angle are well consistent with available experimental values (as shown in Table S2). More importantly, our modified force filed is much better than OPLS-AA force field for describing the interactions between aniline and TIP5P water (deduced from the consistency of predicted $\Delta G^{*}$ values and experimental value). Therefore, the combination of our modified aniline force field and TIP5P water force field could well predict the adsorption process of aniline molecules on the surface of ice.

Table 2. Calculated dipole moment (D), density $\left(\mathrm{g} \mathrm{mL}^{-1}\right)$, evaporation enthalpy (kcal $\mathrm{mol}^{-1}$ ) and heat capacity (cal $\mathrm{mol}^{-1} \mathrm{~K}^{-1}$ ) of aniline with two force fields and corresponding experimental values for aniline.

\begin{tabular}{cccc}
\hline Parameters & $\begin{array}{c}\text { Modified } \\
\text { force field }\end{array}$ & $\begin{array}{c}\text { OPLS-AA } \\
\text { force field }\end{array}$ & Experiment \\
\hline Dipole moment & 1.63 & 1.35 & 1.53 \\
Density & $1.072 \pm 0.004$ & $1.036 \pm 0.002$ & 1.018 \\
Evaporation enthalpy & $14.04 \pm 0.31$ & $13.6 \pm 0.02$ & 13.34 \\
Heat capacity & $43.26 \pm 0.16$ & $37.2 \pm 1.2$ & 45.7 \\
\hline
\end{tabular}

\subsection{Adsorption Isotherm}

The adsorption isotherm of aniline, in the form of the average number $\langle N\rangle$ vs $\mu$ values, is presented in Fig. 2A, and the corresponding detailed data are summarized in Table 3. As shown in Fig. 2A, up to about $\mu=-60.50 \mathrm{~kJ} \mathrm{~mol}^{-1}$, the isotherm shows a rapid increase, corresponding to the building up of the adsorption layer. In the region 
from $\mu=-60.50 \mathrm{~kJ} \mathrm{~mol}^{-1}$ to $-58.22 \mathrm{~kJ} \mathrm{~mol}^{-1}, 2.28 \mathrm{~kJ} \mathrm{~mol}^{-1}$ change in $\mu$ value only results in a rather small change in $\langle N\rangle$, presenting a plateau region. Then, the isotherm suddenly jumps to the condense phase, where the simulation box could be filled with solid aniline as discussed in SI. Therefore, the calculated $\langle N\rangle-\mu$ isotherm for the adsorption of aniline on the ice surface is featured by a plateau mode. Similar cases have also been found in the adsorption of methanol,[15] formic acid,[54] methylamine[25] and benzaldehyde[23] on the ice surface. In addition, the condensation point with the same $\mu$ value in the vapor and condensation phase is somewhere between the $\mu=-58.22$ and $\mu=-57.89 \mathrm{~kJ} \mathrm{~mol}^{-1}$.
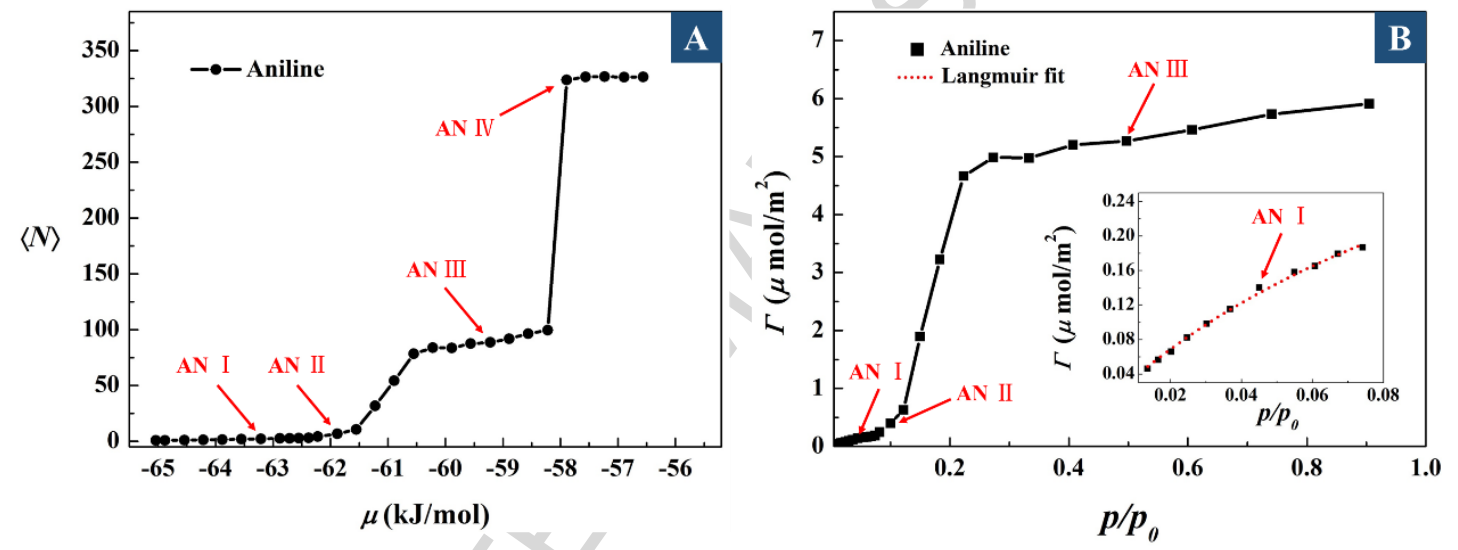

Fig. 2. Adsorption isotherms of aniline (AN) in two forms. (A) average number of anilines $\langle N\rangle$ as a function of $\mu$ values; (B) surface density as a function of the relative pressure. The inset of Fig. 2B shows the Langmuir fitting at low surface coverage.

Table 3. Data corresponding to the adsorption isotherm of aniline in Fig. 2 from GCMC simulations.

\begin{tabular}{cccc}
\hline$\mu\left(\mathrm{kJ} \mathrm{mol}^{-1}\right)$ & $\langle N\rangle$ & $p / p_{0}$ & $\Gamma\left(\mu \mathrm{mol} \cdot \mathrm{m}^{-2}\right)$ \\
\hline-65.04 & 0.776 & $1.36 \times 10^{-2}$ & 0.046 \\
-64.88 & 0.949 & $1.66 \times 10^{-2}$ & 0.056 \\
-64.54 & 1.106 & $2.02 \times 10^{-2}$ & 0.066 \\
-64.21 & 1.385 & $2.47 \times 10^{-2}$ & 0.082 \\
-63.88 & 1.649 & $3.02 \times 10^{-2}$ & 0.098 \\
-63.55 & 1.935 & $3.69 \times 10^{-2}$ & 0.115 \\
\hline
\end{tabular}




\begin{tabular}{|c|c|c|c|}
\hline$-63.21^{a}$ & 2.360 & $4.50 \times 10^{-2}$ & 0.140 \\
\hline-62.88 & 2.657 & $5.50 \times 10^{-2}$ & 0.158 \\
\hline-62.71 & 2.777 & $6.08 \times 10^{-2}$ & 0.165 \\
\hline-62.55 & 2.912 & $6.72 \times 10^{-2}$ & 0.173 \\
\hline-62.38 & 3.139 & $7.43 \times 10^{-2}$ & 0.187 \\
\hline-62.22 & 4.194 & $8.21 \times 10^{-2}$ & 0.249 \\
\hline$-61.88^{b}$ & 6.710 & 0.100 & 0.399 \\
\hline-61.55 & 10.624 & 0.122 & 0.632 \\
\hline-61.22 & 31.870 & 0.150 & 1.895 \\
\hline-60.89 & 54.241 & 0.183 & 3.224 \\
\hline-60.55 & 78.469 & 0.223 & 4.665 \\
\hline-60.22 & 83.839 & 0.273 & 4.984 \\
\hline-59.89 & 83.712 & 0.333 & 4.976 \\
\hline-59.56 & 87.492 & 0.407 & 5.201 \\
\hline$-59.22^{c}$ & 88.615 & 0.497 & 5.268 \\
\hline-58.89 & 91.876 & 0.607 & 5.462 \\
\hline-58.56 & 96.458 & 0.741 & 5.734 \\
\hline-58.22 & 99.491 & 0.905 & 5.914 \\
\hline$-57.89^{d}$ & 323.679 & & \\
\hline-57.56 & 326.362 & & \\
\hline-57.23 & 326.649 & & \\
\hline-56.89 & 326.133 & & \\
\hline-56.56 & 326.297 & & \\
\hline
\end{tabular}

We employed the $\Gamma-p_{\text {rel }}$ isotherm to further explore the adsorption mechanism of aniline in the other view, where $p_{r e l}$ is the relative pressure and $\Gamma$ is the surface density of aniline. In fact, the $\Gamma-p_{\text {rel }}$ isotherm can be converted directly from $\langle N\rangle-\mu$ isotherm. $\Gamma$ is simply calculated by dividing $\langle N\rangle$ by the ice surface area in the GCMC simulation box, which is a linear transformation; $p_{\text {rel }}$ is calculated by normalizing the pressure $(p)$ of the vapor phase by the pressure $\left(p_{0}\right)$ of the condensation point, which is an exponential transformation. The $p_{r e l}$ value is related to $\mu$ through eq. $1,[15]$

$$
p_{r e l}=\frac{p}{p_{0}}=\frac{\exp \left(\mu / k_{\mathrm{B}} T\right)}{\exp \left(\mu_{0} / k_{\mathrm{B}} T\right)}
$$


where $k_{\mathrm{B}}$ is Boltzmann constant, $T$ is temperature and $\mu_{0}$ is a chemical potential corresponding to the adsorption point where the condensation of aniline occurs. Here, we selected $\mu_{0}=-58.06 \mathrm{~kJ} \mathrm{~mol}^{-1}$, corresponding to the midpoint of the $\mu=-58.22$ and $\mu=-57.89 \mathrm{~kJ} \mathrm{~mol}^{-1}$. Actually, $\mu_{0}$ could be one value in the condensation range. Many previous studies $[24,25,56]$ selected the midpoint of the condensation range as $\mu_{0}$ value since it is difficult for the current simulation technology to accurately determine the condensation point. In the form of $\Gamma-p_{\text {rel }}$ isotherm, maximum of $p_{r e l}$ is 1.[24] The $\Gamma-p_{\text {rel }}$ adsorption isotherm of aniline is presented in Fig. $2 \mathrm{~B}$, and the corresponding data are presented in Table 3.

As can be seen in Fig. 2B, the slope of isotherm decreases slightly with $p_{\text {rel }}$ in the $p_{\text {rel }}$ range from 0 to 0.08 . However, the slope increases greatly in the $p_{\text {rel }}$ range from 0.08 to 0.25 . Above $p_{\text {rel }}=0.25$, the slope of the isotherm turns to a small positive value, indicating the $\Gamma$ value increases very slowly with $p_{\text {rel }}$. We also fit the $\Gamma-p_{\text {rel }}$ isotherm of aniline with the Langmuir model (eq. 2) to probe the adsorption character of aniline.[68]

$$
\Gamma=\Gamma_{\max } \frac{p_{r e l} K_{\mathrm{AN}}}{p_{r e l} K_{\mathrm{AN}}+1}
$$

Where $\Gamma_{\max }$ is the surface density of monomolecular adsorption saturation, and $K_{\mathrm{AN}}$ is the partition coefficient. However, the isotherm of aniline shows a non-Langmuir character in the whole considered pressure range as shown in Fig. S3. The failure of the Langmuir fitting probably originates from violation at least one of basic assumptions of the Langmuir isotherm.[24] Further energetic analysis (in section 3.3.4) indicates that the failure results from the existence of nonnegligible lateral interactions between adsorbed aniline at high $p_{\text {rel }}$. Nevertheless, as shown in the inset of Fig. 2B, the isotherm shows Langmuir-like character only when $p_{r e l}<0.08$. Within 
the region of Langmuir-like adsorption isotherm, the fitted $K_{\mathrm{AN}}$ is $7.19 \pm 0.78$ and $\Gamma_{\max }$ is $0.55 \pm 0.04 \mu \mathrm{mol} \cdot \mathrm{m}^{-2}$. In this $p_{\text {rel }}$ range, anilines are adsorbed independently from each other to the sites where they can strongly interact with the ice surface. It deserves mentioning that anilines are adsorbed to various kinds of adsorption sites with similar adsorption energies (see Section 3.3.3), but not one kind of adsorption site. Although the various adsorption sites at the $p_{r e l}<0.08$ range should result in that the adsorption isotherm of aniline can not be fitted well by the Langmuir model, the similar adsorption energies on these sites make the isotherm apparently present Langmuir-like character.
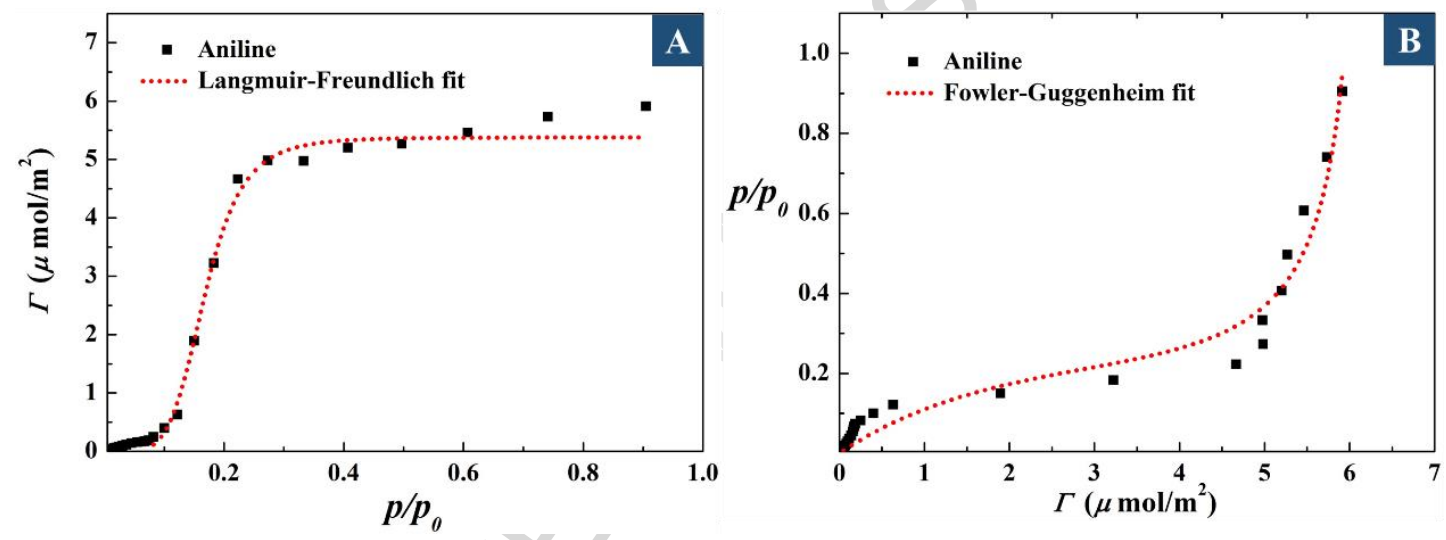

Fig. 3. The simulated adsorption isotherms of aniline fitted by (A) the LangmuirFreundlich model and (B) the Fowler-Guggenheim model.

In addition, we employed various isotherm models, such as Langmuir-Freundlich (L-F, eq. 3),[69] Fowler-Guggenheim (F-G, eq. 4),[70] extended Langmuir (eq. S6)[69] and Brunauer-Emmett-Teller (BET, eq. S7)[54] model to fit the simulated isotherm of aniline over a larger $p_{\text {rel }}$ range.

$$
\Gamma=\Gamma_{\max } \frac{p_{r e l}{ }^{1 / n} K}{1+p_{r e l}^{1 / n} K}
$$




$$
\Gamma=\Gamma_{\max } \frac{p_{r e l} K \exp \left(\frac{\alpha \Gamma}{\Gamma_{\max }}\right)}{1+p_{\text {rel }} K \exp \left(\frac{\alpha \Gamma}{\Gamma_{\max }}\right)}
$$

where $K$ is the partition coefficient, $\Gamma_{\max }$ is the surface density of the saturated monomolecular system, $p_{\text {rel }}$ is the relative pressure, $n$ is Freundlich constant and $\alpha$ is a constant that describes interactions between target molecules in the adsorbed layer. It was found that the simulated isotherm only can be fitted well by L-F and F-G model. The fitting results from L-F and F-G model are shown in Fig. 3 and others were presented in SI. For the L-F model, the fitted $K$ value is $12724.78 \pm 1399.67, n$ is 0.19 \pm 0.02 and $\Gamma_{\max }$ is $5.38 \pm 0.08 \mu \mathrm{mol} \cdot \mathrm{m}^{-2}$. The $\mathrm{R}^{2}(0.988)$ for this fitting is close to 1 . Although the absolute value of the uncertainty of the $K$ value is large, the relative error $(11 \%)$ of the uncertainty could be acceptable. For the F-G model, the $\mathrm{R}^{2}$ for the fitting is 0.957 , and the fitted $K$ is $1.09 \pm 0.32, \alpha$ is $2.84 \pm 0.40$ and $\Gamma_{\max }$ is $6.32 \pm 0.07$ $\mu \mathrm{mol} \cdot \mathrm{m}^{-2}$. Therefore, the simulated isotherm fitted by $\mathrm{F}-\mathrm{G}$ model is not bad. $\Gamma_{\max }$ values from the L-F model $\left(5.38 \mu \mathrm{mol} \cdot \mathrm{m}^{-2}\right)$ and F-G model $\left(6.32 \mu \mathrm{mol} \cdot \mathrm{m}^{-2}\right)$ are comparable with the calculated average surface density $\left(5.28 \mu \mathrm{mol} \cdot \mathrm{m}^{-2}\right)$ of aniline in the first layer from GCMC simulation, indicating that the adsorption layer on the plateau is probably monolayer saturation. In addition, The L-F model is one of the most important multisite adsorption isotherm models for rough surfaces. The F-G model is one of the simplest models taking into account the lateral interactions. The adsorption isotherm of aniline on the ice surface can be well fitted by the L-F and L-G models, implying there are various adsorption sites on the ice surface and nonnegligible interactions between adsorbates.

\subsection{Characterization of the Adsorption Layer}

We have selected four $\mu$ values of aniline representing different stages of the 
adsorption isotherm (Fig. 2) to analyze the characteristics of adsorbed aniline in detail. They are denoted as AN I $\left(\mu=-63.21 \mathrm{~kJ} \mathrm{~mol}^{-1}\right)$, AN II $\left(\mu=-61.88 \mathrm{~kJ} \mathrm{~mol}^{-1}\right)$, AN III $\left(\mu=-59.22 \mathrm{~kJ} \mathrm{~mol}^{-1}\right)$ and $\operatorname{AN~IV~}\left(\mu=-57.89 \mathrm{~kJ} \mathrm{~mol}^{-1}\right)$, and marked in Fig. 2 and Table 3. The top and side view of one random equilibrium snapshot for AN I IV are shown in Fig. 4.
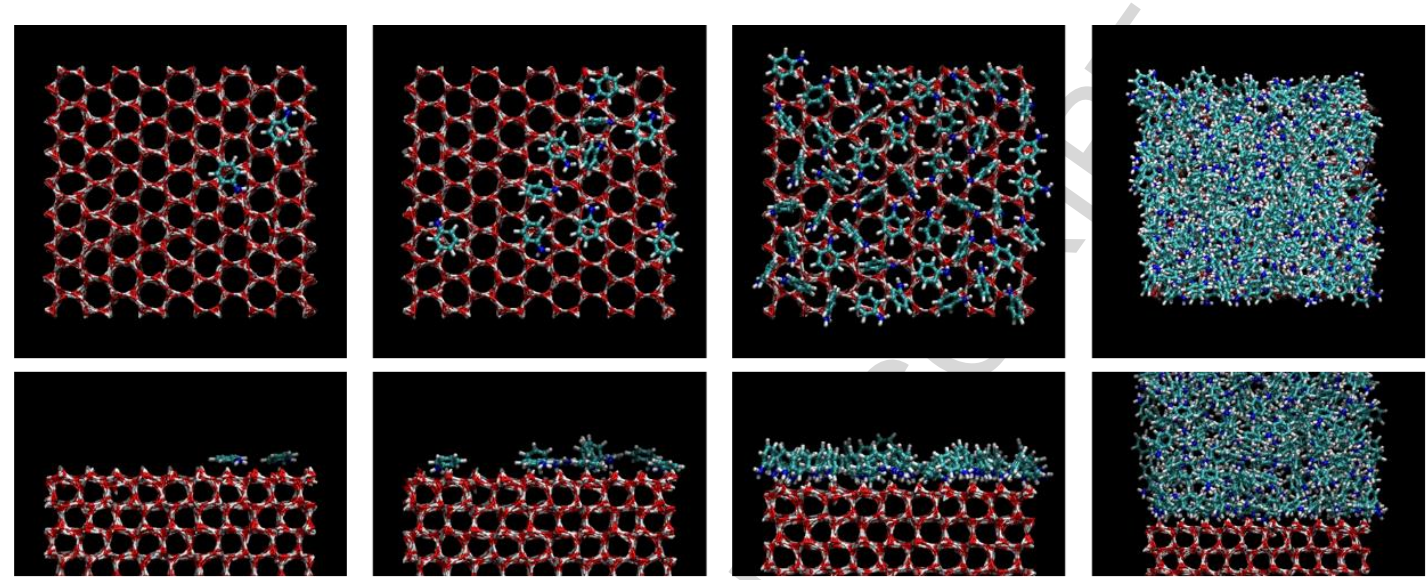

AN I

AN II

AN III

$\mu=-63.21 \mathrm{~kJ} \mathrm{~mol}^{-1}$

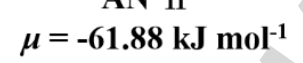

$\mu=-59.22 \mathrm{~kJ} \mathrm{~mol}^{-1}$

AN IV

$\mu=-57.89 \mathrm{~kJ} \mathrm{~mol}^{-1}$

Fig. 4. The top and side view of instantaneous equilibrium snapshots for the adsorption layer of aniline on the ice surface at selected $\mu$ values. $\mathrm{Red}=\mathrm{O}$ atom, cyan $=\mathrm{C}$ atom, blue $=\mathrm{N}$ atom and white $=\mathrm{H}$ atom.

\subsubsection{Density Profiles.}

To characterize the aniline adsorption layer in detail, we also obtained the density profiles (Fig. 5) of the ipso carbon atom $\left(C_{i p s o}\right)$ of aniline for selected systems (AN I IV). As can be seen from Fig. 5, AN II has a higher density profile than AN I, and its density peak position is wider and slightly extends to a larger $\mathrm{X}$ value than that of AN I (a higher $\mathrm{X}$ value indicates that the $C_{i p s o}$ atom of aniline is farther from the ice surface). More importantly, some of the adsorbed aniline molecules in AN II could be aligned differently from those in AN I, which is further confirmed by the following orientation analysis. When moving from $\mathrm{AN}$ II to $\mathrm{AN}$ III, a tail $(\mathrm{X} \approx 38 \sim 40 \AA)$ appears at the outer side of the main density peak of AN III (Fig. 5). This tail presents 
$C_{i p s o}$ and $\mathrm{NH}_{2}$ group away from the ice surface, which is consistent with the results from the following orientation analysis (Section 3.3.2). In system AN IV, there are several peaks, indicating several adsorption layers were formed and therefore aniline is already into the condensed phase.

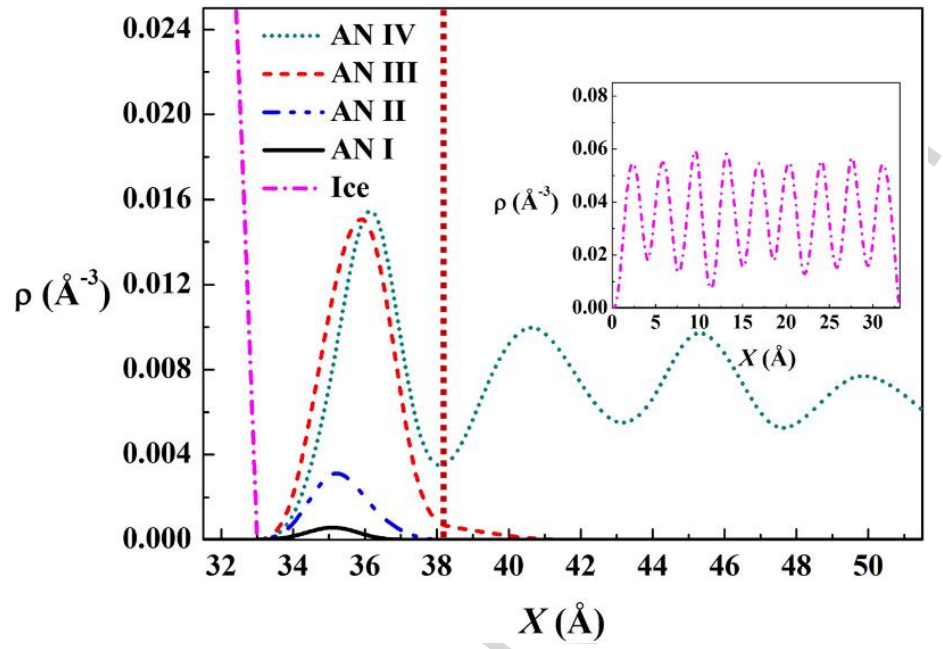

Fig. 5. The density profiles of the ipso carbon atom of the adsorbed anilines in systems AN I IV along the surface normal axis $X$. The density profile of oxygen atoms corresponding to the outmost layer of ice is also shown (dash dot pink line). Inset Figure shows the density profile of oxygen atoms of water molecules obtained in system AN I.

In the following parts, we analyzed the adsorption orientation, hydrogen bonding interactions and adsorption energy of aniline on the ice surface. Similar to previous studies, $[25,39,44,46,71,72]$ the first minimum position (see the vertical short dotted line in Fig. 5) in the density profile of AN IV was defined as the boundary of the first adsorption layer. For the other non-condensed systems AN I III, all aniline molecules adsorbed on the ice surface were selected as the first adsorption layer.

\subsubsection{Orientation of the Adsorbed Molecules.}

Previous studies[23, 25, 46, 71] indicated that polar angles, $v$ and $\varphi$, in cartesian coordinate system fixed to adsorbates can be employed to describe orientation of 
adsorbate relative to the ice surface. Here, to get information about the favorable orientations of the adsorbed aniline molecules, the normal vector $X$ of the ice surface is defined by the ice surface pointing to the air, while cartesian coordinate system fixed to aniline molecules is defined as follows: starting from the $\mathrm{N}$ atom (origin of the coordinate), $x$ axis is perpendicular to the phenyl plane of aniline, $y$ axis is parallel to the line connecting two hydrogen atoms on the amino group, and the $\mathrm{N}-\mathrm{C}_{i p s o}$ bond is selected as $z$ axis (see Fig. 6). Accordingly, $v$ is the angle between $X$ and the $z$ axis, and $\varphi$ is the angle between the projection of the normal vector $X$ in the $x y$ plane and the $x$ axis.

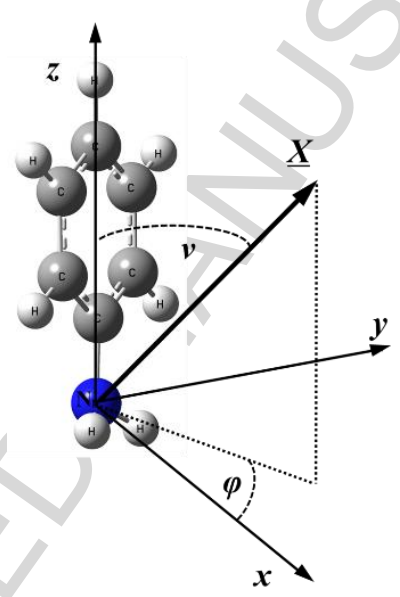

Fig. 6. Cartesian coordinate system definition for orientational analysis of aniline molecule on the ice surface. $v$ and $\varphi$ are polar angles, and $X$ is surface normal vector of ice.

The $P(\cos v, \varphi)$ orientational maps for AN I IV systems are shown in Fig. 7. As can be seen, orientations corresponding to $\cos v$ values in the range of $-0.5 \sim 0.5$ occur with high probability in AN I IV systems. Therefore, in these orientations, the inclination angle of the $\mathrm{N}-\mathrm{C}_{i p s o}$ bond to the ice surface is between $0 \sim 30^{\circ}$. In $\mathrm{AN}$ I system, the most favorable orientation (marked here as orientation A in Fig. 7) corresponds to a $\varphi$ value of $180^{\circ}$ and cosv value of approximate 0.25 , i.e. the two $\mathrm{H}$ atoms of $\mathrm{NH}_{2}$ equally point toward the ice surface (making the lone pair electrons of 
$\mathrm{N}$-atom point outward from ice surface), the angle between $\mathrm{N}-\mathrm{C}_{i p s o}$ bond and the ice surface is about $15^{\circ}$. We noted that there is a small proportion of the orientation (marked as orientation A1 in Fig. 7) which $\varphi$ value become smaller relative to orientation A. Thus, the two $\mathrm{H}$-atoms of $\mathrm{NH}_{2}$ can not equally point toward the ice surface, which could make orientation A1 form only one $\mathrm{N}-\mathrm{H} \bullet \bullet \mathrm{O}$ hydrogen bond. Another favorable orientation (marked as orientation B in Fig. 7) that exists in AN I corresponds to a $\varphi$ value near $0^{\circ}$ and $\cos v$ value of near 0 , i.e. the two H-atoms of $\mathrm{NH}_{2}$ are equally away from the ice surface (making the lone pair electrons of $\mathrm{N}$-atom point toward ice surface) and $\mathrm{N}-\mathrm{C}_{i p s o}$ bond is parallel to the ice surface. With the increasing number of adsorbed aniline, relative occurring probability for orientation A is progressively decreased. However, the orientation B is progressively increased. In addition, from AN I to AN II IV, the orientation with a small tilt of the molecule away from the most favorable orientation A and B gradually takes some population, e.g. A1, A2, B1 and B2 in Fig 7. Specially for AN IV, orientation with a $\varphi$ value close to $90^{\circ}$ (marked as $\mathrm{C} 1\left(\varphi<90^{\circ}\right)$ and $\mathrm{C} 2\left(\varphi>90^{\circ}\right)$ in Fig. 7), corresponding the line connecting the two $\mathrm{H}$-atoms of the $\mathrm{NH}_{2}$ group almost perpendicular to ice surface. It deserves mentioning that the orientations $\mathrm{C} 1$ and $\mathrm{C} 2$ only occur in AN IV system.
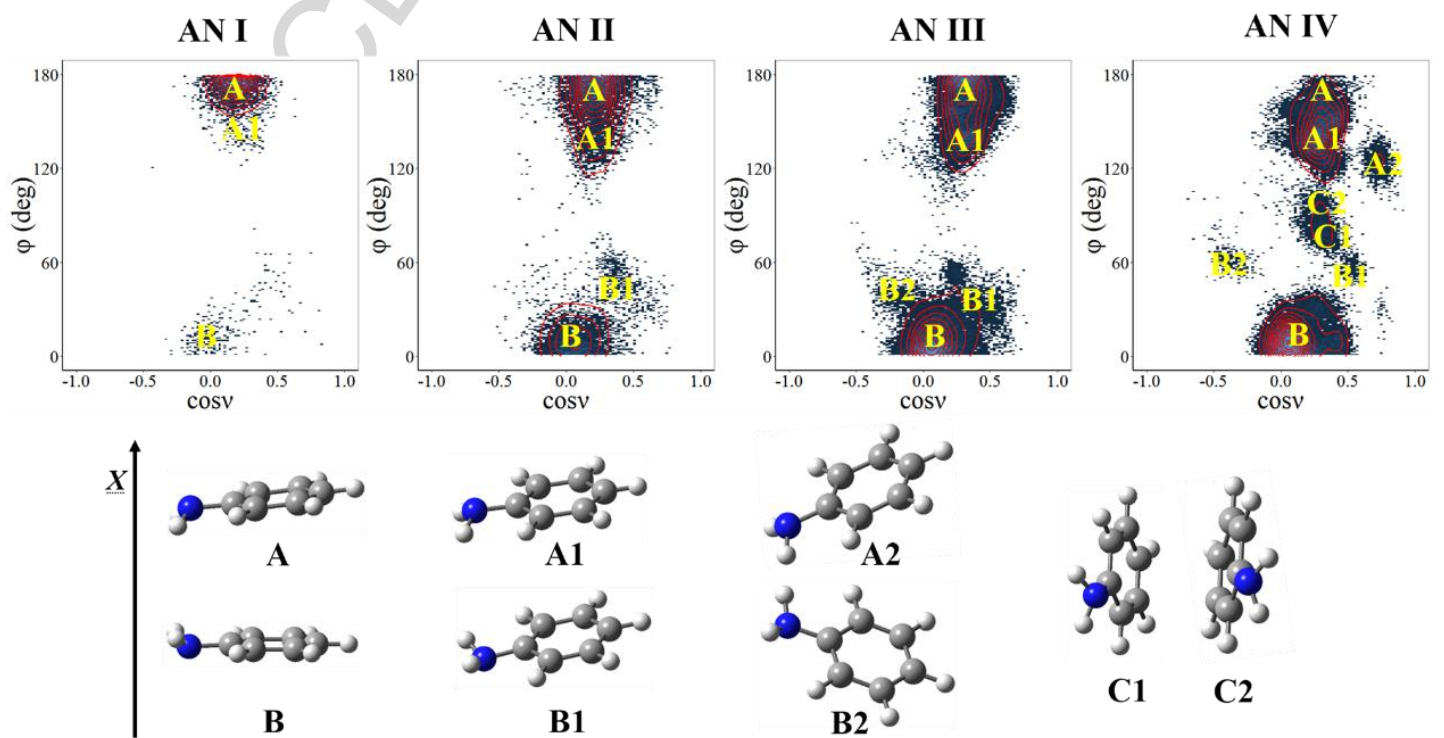
Fig. 7. Orientational maps of aniline molecules for AN I IV (upper part). The orientation distribution of aniline is described by red contours. The dense areas of the contours for the favorable aniline orientations are marked with A, A1, A2, B, B1, B2, $\mathrm{C} 1$ and $\mathrm{C} 2$ and corresponding configurations are presented in lower part.

\subsubsection{Hydrogen-bonding type of $-\mathrm{NH}_{2}$ of aniline with the ice surface}

Based on above analysis of the orientational maps, the hydrogen bonds formed between $-\mathrm{NH}_{2}$ group of aniline and ice surface could play an important role in the interactions of aniline with ice surface. According to identified orientations of aniline, the $-\mathrm{NH}_{2}$ group of aniline could form four types of hydrogen bonds with ice surface. The possible configurations with four types of hydrogen bonds are presented in Fig. 8, where Config 1 corresponds to the orientation $\mathrm{A} 1 / \mathrm{A} 2$ and part of $\mathrm{C} 1 / \mathrm{C} 2$, Config 2 to orientation A, Config 3 to B/B1/B2 and Config 4 to part of $\mathrm{C} 1 / \mathrm{C} 2$ in Fig. 7. To further confirm the formation of these hydrogen bonds and identify the main hydrogenbonding type of aniline $-\mathrm{NH}_{2}$ with the ice surface, we statistically analyzed the formation probability of these four types of hydrogen bonds. Here, the hydrogen bond is uniquely defined by two distance criteria: the distance between two heavy atoms in hydrogen acceptor and the donor $<3.5 \AA$, and the distance between the bonding $\mathrm{H}$ and acceptor $\mathrm{N}$ or $\mathrm{O}$ atom $<2.45 \AA .[73,74]$ Histograms for the probability of four types of hydrogen bonds and non-hydrogen bonds are presented in Fig. 9.

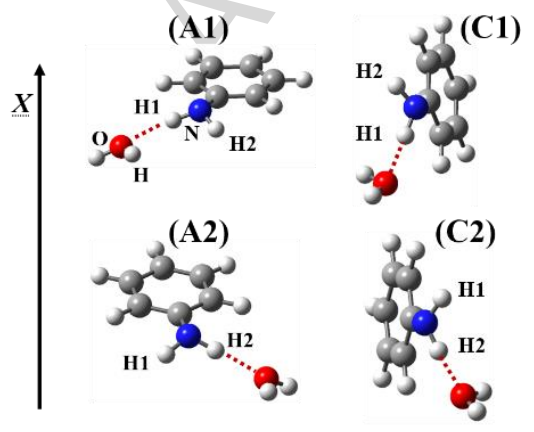

Config 1 $\mathrm{N}-\mathrm{H} 1 \cdots \mathrm{O}$ or $\mathrm{N}-\mathrm{H} 2 \cdots \mathrm{O}$

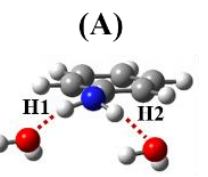

Config 2 $\mathrm{N}-\mathrm{H} 1 \cdots \mathrm{O}$ and $\mathrm{N}-\mathrm{H} 2 \cdots \mathrm{O}$
(B)

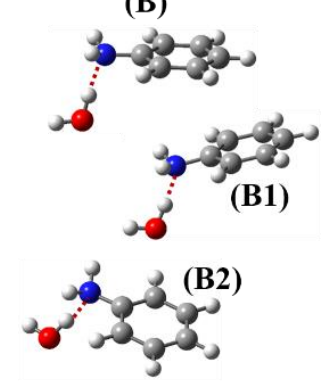

Config 3

N•••H-O

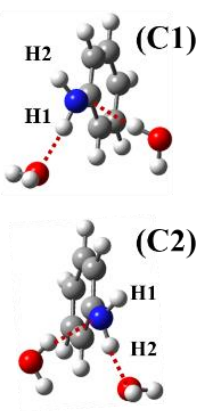

Config 4 $\mathrm{N}-\mathrm{H} 1(2) \cdots \mathrm{O}$ and $\mathrm{N} \cdots \mathrm{H}-\mathrm{O}$ 
Fig. 8. Four types of hydrogen bonds formed between $-\mathrm{NH}_{2}$ of aniline and ice surface. The corresponding configurations (Config 1-4) of the formed four types of hydrogen bonds are consistent with the orientational maps of the aniline in Fig. 7.

As can be seen from Fig. 9, the probability of Config 2 is the highest, followed by Config 1 for AN I. However, Config 3 and NONE (configurations without hydrogen bonds) is pretty small. Therefore, at a low adsorbate coverage, aniline dominantly interacts with the ice surface by $\mathrm{N}-\mathrm{H} 1 \cdots \cdot \mathrm{O}$ and $\mathrm{N}-\mathrm{H} 2 \cdots \cdot \mathrm{O}$ hydrogen bonds, followed by $\mathrm{N}-\mathrm{H} 1 / \mathrm{H} 2 \cdot \bullet \bullet \mathrm{O}$ and $\mathrm{N} \bullet \bullet \cdot \mathrm{H}-\mathrm{O}$ hydrogen bond. This also indicates that there are several adsorption sites in AN I, not only one. With increased coverage from AN I to AN IV, the probability of Config 2 is gradually decreased, while the probability of Config 3 is increased. For AN III and AN IV, the probability of Config 3 becomes higher than that of Config 2. This could indicate that when the number of adsorbed aniline increases, aniline tends to spare more sites to interact with other adsorbed anilines to achieve lower adsorption energies, agreeing well with the decreased the interaction energy of aniline molecules themselves with increased coverage (Section for Energetics of Adsorption). Moreover, the probability of Config 4 is zero, indicating no double hydrogen bonds with $\mathrm{N}-\mathrm{H} \bullet \bullet \mathrm{O}$ and $\mathrm{N} \bullet \bullet \mathrm{H}-\mathrm{O}$ are formed between $-\mathrm{NH}_{2}$ and ice surface. A qualitatively consistent conclusion was found when the hydrogen bond is defined by a loose distance and angular criterion (SI). However, the definition of hydrogen bond can influence quantitative comparison of occurring probability of various configuration, e.g. the probability of Config 1 is lower than that of the probability of Config 3 with loose hydrogen bond definition. We also noted that the results for occurring probability ranking of various configurations under a normal distance and angular criterion are different from that under a loose distance and angular criterion, especially for Config 1 and Config 2 in AN I. The change in 
occurring probability ranking of Config 1 and Config 2 from loose to normal distance and angular criterion indicates that one or two $\mathrm{N}-\mathrm{H} \bullet \bullet \mathrm{O}$ hydrogen bonds are distorted (details in SI). In addition, it deserves mentioning that the hydrogen-bonding type of $-\mathrm{NH}_{2}$ of aniline with ice surface is different from that for methylamine where the dominant adsorption configuration involves simultaneous formation of $\mathrm{N} \cdots \cdot \mathrm{H}-\mathrm{O}$ and $\mathrm{N}-\mathrm{H} 1 \cdots \mathrm{O}$ hydrogen bonds (like Config 4 in Fig. 8) at low coverage. The difference could result from the preference of the phenyl ring to lay parallel with the surface, which restricts the orientation of the $\mathrm{NH}_{2}$ group.

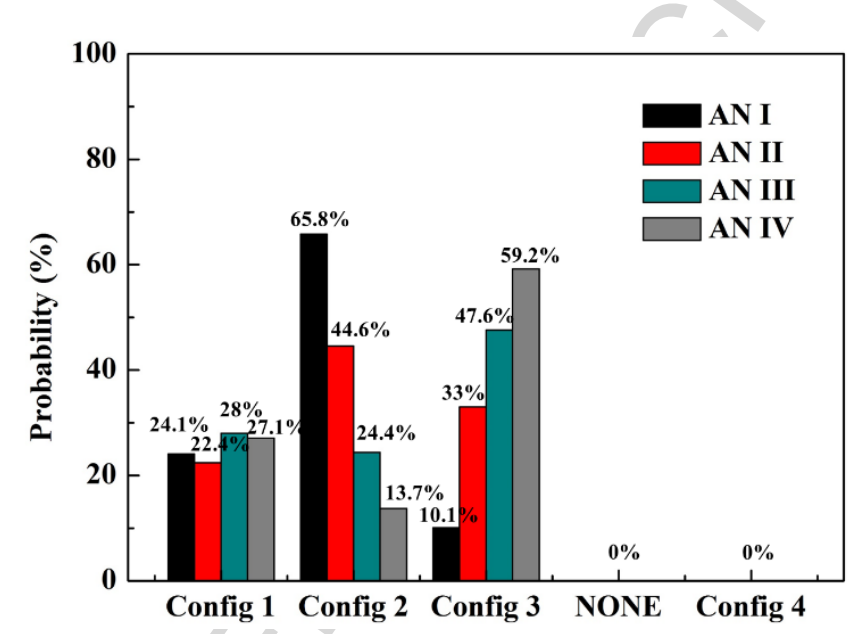

Fig. 9. Histograms of probability of four types of hydrogen bonds formed between $-\mathrm{NH}_{2}$ of aniline and the ice surface and non-hydrogen bonds. The hydrogen bond is uniquely defined by two distance criteria: the distance between two heavy atoms in hydrogen acceptor and the donor $<3.5 \AA$, and the distance between the bonding $\mathrm{H}$ and acceptor $\mathrm{N}$ or $\mathrm{O}$ atom $<2.45 \AA$ A. The symbols "Config 1", "Config 2", "Config 3" and "Config 4" correspond the configurations in Fig. 8 and NONE corresponds to configuration without hydrogen bonds.

\subsubsection{Energetics of Adsorption}

Interaction energies of the adsorbed anilines with the ice phase $U_{b}^{i c e}$, with the other adsorbed anilines $U_{b}^{\text {lat }}$ and total binding energies of adsorbed anilines $\left(U_{b}=\right.$ $\left.U_{b}^{i c e}+U_{b}^{\text {lat }}\right)$ are calculated to probe the energetic features of the adsorption. The Fig. 
10 presented the distributions of $U_{b}^{i c e}, U_{b}^{\text {lat }}$ and $U_{b}$ for systems AN I IV. As can be seen in Fig. 10, the distribution of $U_{b}^{\text {lat }}$ presents a high and sharp peak at around $0 \mathrm{~kJ}$ $\mathrm{mol}^{-1}$ for AN I with a low surface coverage, indicating the aniline molecules are adsorbed independently from each other. Therefore, the $U_{b}^{i c e}$ is dominant contributor to $U_{b}$ for AN I. The distribution of $U_{b}^{i c e}$ is broad, which could be caused by an uneven adsorption of aniline on ice surface (detailed in SI). The mean value of $U_{b}^{i c e}$ is calculated to be $-65.91 \pm 0.22 \mathrm{~kJ} \mathrm{~mol}^{-1}$ (error corresponds to the $95 \%$ confidence level). As discussed in Section 3.3.3, there are several configurations in AN I. Here, we analyzed the energetic information of two typical configurations Config 2 and Config 3. Config 2 and Config 3 are randomly selected from adsorption configurations of AN I. It was found that $U_{b}^{i c e}$ of Config 2 and Config 3 are close although the Config 2 is a little bit higher in magnitude than Config 3. Interestingly, it was found that calculated interaction energy $(-36.02 \mathrm{~kJ} / \mathrm{mol})$ between the phenyl ring and the ice surface contributes more to $U_{b}{ }^{i c e}$ than $\mathrm{N} \bullet \bullet \cdot \mathrm{H}-\mathrm{O}$ bond $(-27.09 \mathrm{~kJ} / \mathrm{mol})$ for Config 3, with an approximate method (detailed in SI). However, the interaction energy $(-28.91 \mathrm{~kJ} / \mathrm{mol})$ between the phenyl ring and the ice surface contributes less to $U_{b}^{i c e}$ than two $\mathrm{N}-\mathrm{H} \bullet \bullet \mathrm{O}$ bonds $(-35.74 \mathrm{~kJ} / \mathrm{mol})$ for Config 2 . Obviously, the interaction energy of phenyl ring and $-\mathrm{NH}_{2}$ moiety of aniline with ice surface varies with specific adsorption configuration. Therefore, the low energy for specific adsorption configuration should be reached by compromising interaction between phenyl ring-ice and $-\mathrm{NH}_{2}-$ ice to make aniline better adapt to ice surface.

In the system AN II, the peaks of distribution of $U_{b}^{\text {lat }}$ and $U_{b}$ shift to lower energy regions, while the peak of $U_{b}^{i c e}$ shifts to higher energy regions, compared with the corresponding peak in AN I. Specially, increase in $U_{b}^{\text {lat }}$ and decrease in $U_{b}^{i c e}$ in AN II indicate that attractive interaction among the adsorbed aniline molecules makes a part 
of the aniline molecules be adsorbed onto sites which could not lead to the strongest interaction between ice and aniline. This is also the reason for the deviation from Langmuir-like adsorption isotherm at high $p_{\text {rel }}$ (Fig. 2B). When moving from AN II to AN III and AN IV, the peaks of $P\left(U_{b}\right)$ and $P\left(U_{b}^{\text {lat }}\right)$ are gradually shifted to lower energy regions and the peaks of $P\left(U_{b}^{i c e}\right)$ to higher energy regions. The $U_{b}^{\text {lat }}$ values are approximately -17 and $-28 \mathrm{~kJ} / \mathrm{mol}$ for AN II and AN III, respectively, indicating there is a strong interaction between two adsorbed aniline molecules. By randomly checking adsorption configuration, it was found that $\mathrm{N}-\mathrm{H} \bullet \bullet \cdot \mathrm{N}$ and $\mathrm{N}-\mathrm{H} \cdot \bullet \bullet \pi$ bonds can be formed between two adsorbates. Overall, with the increased number of adsorbed anilines, $U_{b}^{\text {lat }}$ and $U_{b}$ decrease while $U_{b}^{i c e}$ increases.

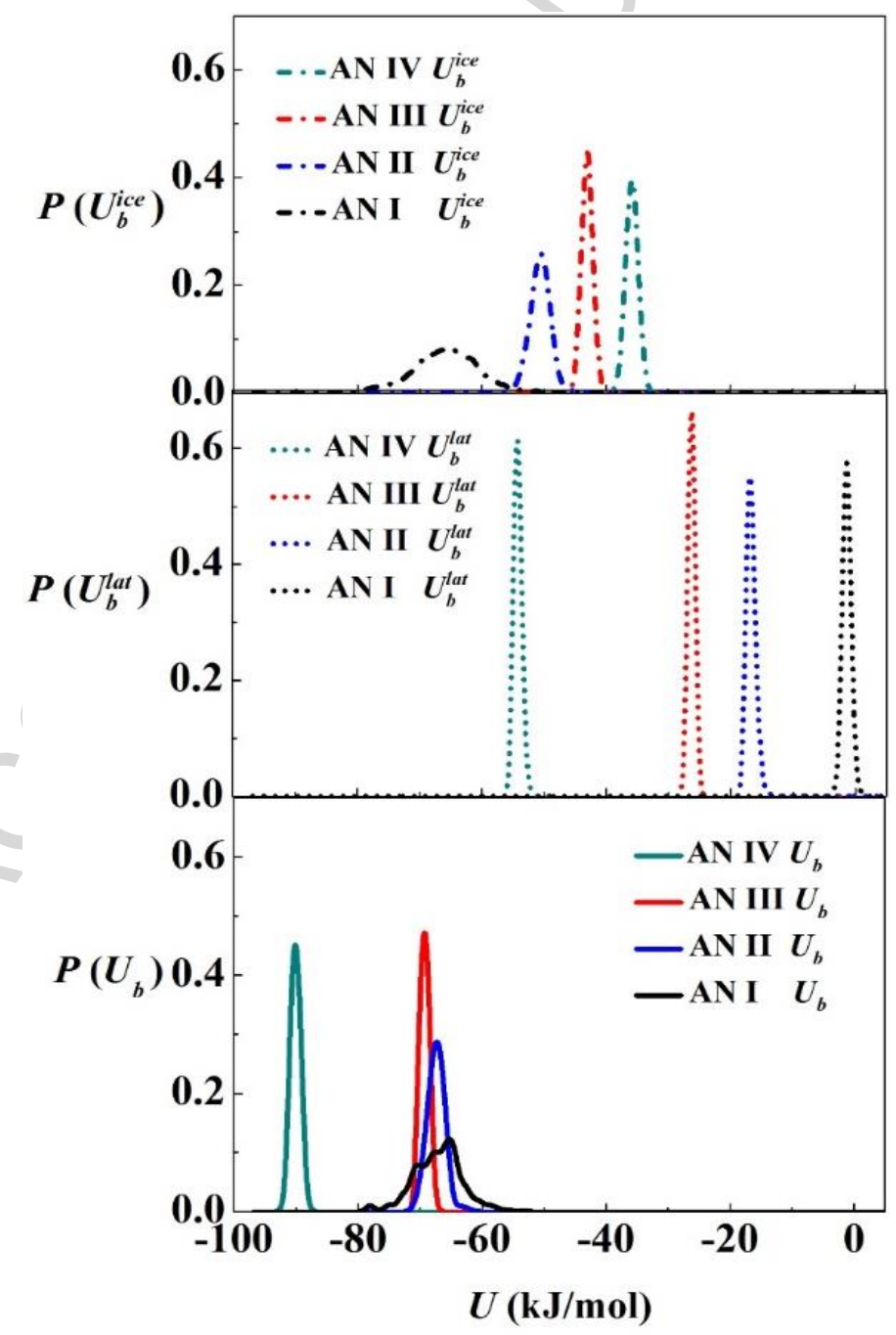

Fig. 10. Distribution of the total binding energy of aniline molecules $\left(U_{b}\right)$ on the 
surface of ice, the interaction energy among adsorbed aniline molecules $\left(U_{b}^{\text {lat }}\right)$ and aniline molecules with the ice surface $\left(U_{b}^{i c e}\right)$ in AN I IV.

\subsection{Quantum Chemistry Calculations.}

Similar to our previous study on the adsorption of nitrobenzene on ice surface, we also calculate $U_{b}^{i c e}$ using quantum chemistry calculation to further test the reliability of the modified force field of aniline and adsorption results. Quantum chemistry calculation scheme including ice surface model and calculation method for $U_{b}^{i c e}$ is identical with our previous study on nitrobenzene.[39] More details can be found in SI. In short, the calculations were performed in Gaussian 09 software package.[64] The geometry optimizations and single-point energy calculations were performed at the M062X/6-31+G(d,p) level and M062X/6-311++G(3df,2pd), respectively. The $\mathrm{H}_{2} \mathrm{O}-48$ cluster consisting of two layers was selected as ice surface model. It deserves mentioning that we did not consider the configuration involving the interaction of aniline with boundary $\mathrm{O}$-atoms due to possible artificial boundary condition in the $\mathrm{H}_{2} \mathrm{O}-48$ cluster model. The configuration with the lowest Gibbs free energy was determined as the most stable adsorption configuration (Fig. 11) among the 18 initial structures. The Gibbs free energy was calculated by adding the electronic energy into the thermal energies and entropic contributions obtained via the molecular partition functions. All Gibbs free energy calculations are performed at $200 \mathrm{~K}$, which is consistent with the temperature of the GCMC simulations. As shown in Fig. 11, the aniline is almost parallel to the surface of ice, where the H-atoms of phenyl group point toward $\mathrm{O}$-atom of $\mathrm{H}_{2} \mathrm{O}$ and two $\mathrm{H}$-atoms of the $-\mathrm{NH}_{2}$ group simultaneously form hydrogen bonds with two different $\mathrm{H}_{2} \mathrm{O}$ molecules on the surface of ice. The stable adsorption configuration of aniline computed by the quantum chemistry method is consistent with Config 2 in AN I (Fig. 8) from GCMC results. Moreover, $U_{b}^{i c e}$ from 
quantum chemistry calculations $\left(-69.34 \mathrm{~kJ} \mathrm{~mol}^{-1}\right)$ agrees well with that in AN I from GCMC simulations $\left(-65.91 \pm 0.22 \mathrm{~kJ} \mathrm{~mol}^{-1}\right)$. We noted that Config 2 is dominant one in AN I and $U_{b}^{i c e}$ of other adsorption configurations in AN I should be similar to Config 2 since AN I is one point among all points that follow the Langmuir isotherm. Therefore, although $U_{b}^{i c e}$ for AN I is statistically average in the GCMC simulation, it can be compared with that from quantum chemistry calculations. The good agreement between two methods further confirms the rationality of our modified force field of aniline and the GCMC simulations.

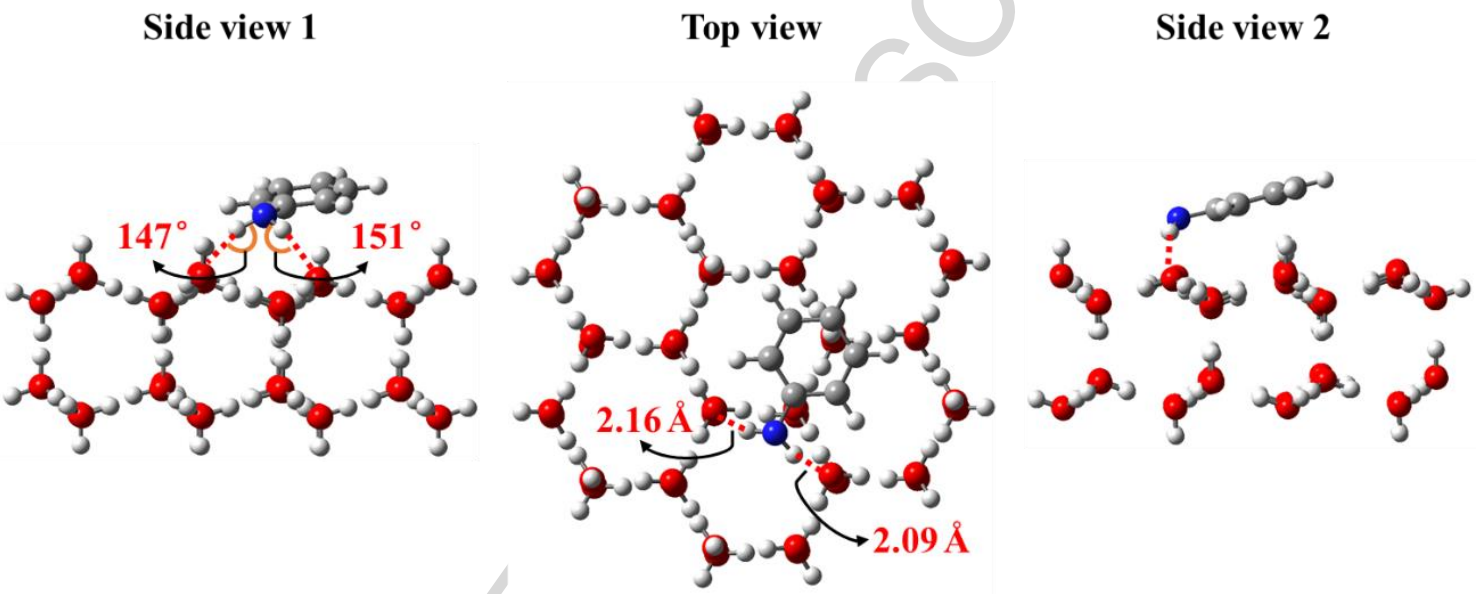

Fig. 11. The top view and side views of the most stable configuration of aniline absorbed on the surface of ice obtained from quantum chemistry calculation.

\subsection{Comparison with other Adsorbates on the Surface of Ice}

To further probe the substitution effect on the adsorption of benzene on ice surface, we compare the adsorption mechanism of aniline with benzene,[24] nitrobenzene[39] and benzaldehyde[23] on the ice surface. The adsorption isotherms of aniline is quite different from that found for benzene and nitrobenzene, which present simple adsorption isotherms, i.e., the number of adsorbates increase with relative pressure before a condensed point.[39] However, similar adsorption isotherm has been found for benzaldehyde[23] that presents a "saturation plateau". However, 
different from benzaldehyde, it is monomolecular adsorption for aniline in the saturation plateau. Therefore, it is anticipated that the different adsorption mechanisms of substituted benzene on the surface of ice depends on the substituents. By comparing $U_{b}^{\text {lat }}$ and $U_{b}^{i c e}$ values among these four aromatics, we found the $U_{b}^{\text {lat }}$ values for adsorbates with different adsorption isotherm differ greatly, i.e. $U_{b}^{\text {lat }}$ values for benzene $\left(-18 \mathrm{~kJ} \cdot \mathrm{mol}^{-1}\right)$ and nitrobenzene $\left(-10 \mathrm{~kJ} \cdot \mathrm{mol}^{-1}\right)$ with simple adsorption isotherm are lower in magnitude than those of benzaldehyde $\left(-30 \mathrm{~kJ} \cdot \mathrm{mol}^{-1}\right)$ and aniline $\left(-28 \mathrm{~kJ} \cdot \mathrm{mol}^{-1}\right)$ with a "saturation plateau". Although there is no statistical significance, this could give a hint that the difference in $U_{b}^{\text {lat }}$ for these four adsorbates could be one reason for their different adsorption mechanisms.

It is intertesting to compare the $U_{b}^{i c e}$ of aniline with those of acidic, base, and neutral molecules investigated by previous studies.[15, 25, 54-57] The order of $U_{b}^{i c e}$ at low surface coverage follows nitrobenzene $(-76 \mathrm{~kJ} / \mathrm{mol})<$ aniline $(-66 \mathrm{~kJ} / \mathrm{mol})<$ formic acid $(-63 \mathrm{~kJ} / \mathrm{mol})<$ benzaldehyde $(-59 \mathrm{~kJ} / \mathrm{mol})<$ methylamine $(-55 \mathrm{~kJ} / \mathrm{mol})<$ methanol $(-54 \mathrm{~kJ} / \mathrm{mol})<$ acetone $(-53 \mathrm{~kJ} / \mathrm{mol})<$ acetaldehyde $(-35 \mathrm{~kJ} / \mathrm{mol})<$ formaldehyde $(-30 \mathrm{~kJ} / \mathrm{mol})$. Although no strict relationship between the structure of adsorbates and $U_{b}^{i c e}$ was found, the ability of a functional group to interact with ice surface, dipole moment and the number of the functional group which can interact with ice surface greatly affect $U_{b}^{i c e}$. This is the reason that nitrobenzene and aniline owns the lower $U_{b}^{i c e}$ since aniline includes $-\mathrm{NH}_{2}$ group, a strong hydrogen bond donor and acceptor, and $-\mathrm{C}_{6} \mathrm{H}_{5}$ group, being able to form $\mathrm{O}-\mathrm{H} \bullet \bullet \pi$ bond with ice surface and nitrobenzene has high polarity besides $-\mathrm{C}_{6} \mathrm{H}_{5}$ group.

\section{CONCLUSIONS}

In this study, we investigated the adsorption of aniline, one kind of $\mathrm{NH}_{x^{-}}$ containing compound, on the surface of ice under tropospheric conditions. The 
GCMC simulation was performed with the modified force field of aniline and TIP5P water force field. We found that the adsorption isotherm of aniline presented a "monolayer saturation plateau" starting with a steep increase, then a plateau, and finally a condensation phase. The adsorption isotherm of aniline is similar to that of benzaldehyde adsorption on the ice surface, however, quite different from the cases of benzene and nitrobenzene. Under very low surface coverage, the adsorption isotherm follows an apparent Langmuir type. Within the range of the apparent Langmuir-type adsorption isotherm, adsorbed anilines are strongly attached to various adsorption sites, where most anilines are almost parallel to the surface of ice and form two $\mathrm{N}-\mathrm{H} \bullet \bullet \mathrm{O}$ hydrogen bonds. With the increase of coverage, some of the adsorbed aniline molecules fail to take adsorption sites which could lead to the strongest interaction between ice and aniline due to the attractive interaction between the adsorbates, resulting in a deviation from the apparent Langmuir type adsorption isotherm. In addition, the adsorption energy of aniline agrees well with the value obtained by validating quantum chemistry method, which further verified the rationality of our modified force field of aniline and reliability of the GCMC simulation.

\section{ASSOCIATED CONTENT}

Supporting Information. The details for the potential of mean force (PMF) calculation, computational details of several physicochemical parameters of the aniline, fitting the adsorption isotherm of aniline with various models, the geometry of aniline, hydrogen-bonding type analysis, the possible reason for broad distribution of $U_{b}^{i c e}$ and the details for quantum chemistry calculations. This material is available free of charge via the Internet at https://www.elsevier.com.

\section{AUTHOR INFORMATION}




\section{Corresponding Author}

*Phone/fax: +86-411-84707844; e-mail: hbxie@dlut.edu.cn.

\section{ACKNOWLEDGEMENTS}

We are grateful to Prof. Mihaly Mezei for providing MMC Monte Carlo program and Computational Guidance. This study was supported by the National Natural Science Foundation of China [21677028 and 21477015], the Major International (Regional) Joint Research Project [21661142001], the Program for Changjiang Scholars and Innovative Research Team in University [IRT_13R05] and the Programme of Introducing Talents of Discipline to Universities [B13012]. We thank Supercomputing Center of Dalian University of Technology for part of computing resources. 


\section{REFERENCES}

[1] F. Dominé, P.B. Shepson, Science 297 (2002) 1506-1510.

[2] T. Bartels-Rausch, H.W. Jacobi, T.F. Kahan, J.L. Thomas, E.S. Thomson, J.P.D. Abbatt, M. Ammann, J.R. Blackford, H. Bluhm, C. Boxe, F. Domine, M.M. Frey, I. Gladich, M.I. Guzmán, D. Heger, T. Huthwelker, P. Klán, W.F. Kuhs, M.H. Kuo, S. Maus, S.G. Moussa, V.F. McNeill, J.T. Newberg, J.B.C. Pettersson, M. Roeselová, J.R. Sodeau, Atmos. Chem. Phys. 14 (2014) 1587-1633.

[3] T. Bartels-Rausch, Nature 494 (2013) 27-29.

[4] V.F. McNeill, A.M. Grannas, J.P.D. Abbatt, M. Ammann, P. Ariya, T. BartelsRausch, F. Domine, D.J. Donaldson, M.I. Guzman, D. Heger, T.F. Kahan, P. Klán, S. Masclin, C. Toubin, D. Voisin, Atmos. Chem. Phys. 12 (2012) 9653-9678.

[5] T. Bartels-Rausch, H.W. Jacobi, T.F. Kahan, J.L. Thomas, E.S. Thomson, J.P.D. Abbatt, M. Ammann, J.R. Blackford, H. Bluhm, C. Boxe, F. Domine, M.M. Frey, I. Gladich, M.I. Guzmán, D. Heger, T. Huthwelker, P. Klán, W.F. Kuhs, M.H. Kuo, S. Maus, S.G. Moussa, V.F. McNeill, J.T. Newberg, J.B.C. Pettersson, M. Roeselová, J.R. Sodeau, Atmos. Chem. Phys. Discuss. 12 (2012) 30409-30541.

[6] J.T. Hoff, F. Wania, D. Mackay, R. Gillham, Environ. Sci. Technol. 29 (1995) 1982-1989.

[7] T.F. Kahan, R. Zhao, D.J. Donaldson, Atmos. Chem. Phys. 10 (2010) 843-854.

[8] J.P.D. Abbatt, Chem. Rev. 103 (2003) 4783-4800.

[9] S. Picaud, P. Jedlovszky, Molecular Simulation 44 (2018) 1-14.

[10] T.F. Kahan, S.N. Wren, D.J. Donaldson, Acc. Chem. Res. 47 (2014) 1587-1594.

[11] R.B. Gerber, M.E. Varner, A.D. Hammerich, S. Riikonen, G. Murdachaew, D. Shemesh, B.J. Finlayson-Pitts, Acc. Chem. Res. 48 (2015) 399-406.

[12] L. Arellano, P. Fernandez, J. Tatosova, E. Stuchlik, J.O. Grimalt, Environ. Sci. Technol. 45 (2011) 9268-9275.

[13] K.J. Hageman, W.D. Hafner, D.H. Campbell, D.A. Jaffe, D.H. Landers, S.L. Massey Simonich, Environ. Sci. Technol. 44 (2010) 4452-4458.

[14] T. Huthwelker, M. Ammann, T. Peter, Chem. Rev. 106 (2006) 1375-1444.

[15] P. Jedlovszky, L. Partay, P.N.M. Hoang, S. Picaud, P. von Hessberg, J.N. Crowley, J. Am. Chem. Soc. 128 (2006) 15300-15309.

[16] M.R. Christine, G. Kai-Uwe, P.S. Rene, Environ. Sci. Technol. 38 (2004) 40784084.

[17] X. Ge, A.S. Wexler, S.L. Clegg, Atmos. Environ. 45 (2011) 524-546.

[18] H.B. Xie, C. Li, N. He, C. Wang, S.W. Zhang, J.W. Chen, Environ. Sci. Technol. 48 (2014) 1700-1706.

[19] H.B. Xie, F.F. Ma, Y.F. Wang, N. He, Q. Yu, J.W. Chen, Environ. Sci. Technol. 49 (2015) 13246-13255.

[20] H.B. Xie, F.F. Ma, Q. Yu, N. He, J.W. Chen, J. Phys. Chem. A 121 (2017) 16571665.

[21] H.B. Xie, J. Elm, R. Halonen, N. Myllys, T. Kurten, M. Kulmala, H. Vehkamaki, Environ. Sci. Technol. 51 (2017) 8422-8431.

[22] P. Corrochano, D. Nachtigallova, P. Klan, Environ. Sci. Technol. 51 (2017) 13763-13770.

[23] M. Petitjean, G. Hantal, C. Chauvin, P. Mirabel, S.L. Calve, P.N.M. Hoang, S. Picaud, P. Jedlovszky, Langmuir. 26 (2010) 9596-9606.

[24] Z.E. Mészár, G. Hantal, S. Picaud, P. Jedlovszky, J. Phys. Chem. C 117 (2013) 6719-6729.

[25] V. Szentirmai, M. Szőri, S. Picaud, P. Jedlovszky, J. Phys. Chem. C 120 (2016) 23480-23489. 
[26] J. Al-Nu'airat, M. Altarawneh, X. Gao, P.R. Westmoreland, B.Z. Dlugogorski, J. Phys. Chem. A 121 (2017) 3199-3206.

[27] A.J. Salter-Blanc, E.J. Bylaska, M.A. Lyon, S.C. Ness, P.G. Tratnyek, Environ.

Sci. Technol. 50 (2016) 5094-5102.

[28] X. Wang, Y.W. Li, J. Mol. Catal. A-Chem. 420 (2016) 56-65.

[29] G.Q. Tang, J. Sun, F.K. Wu, Y. Sun, X.W. Zhu, Y.J. Geng, Y.S. Wang, Sci. China Chem. 58 (2015) 1416-1425.

[30] J.P. Zhu, B. Aikawa, Environ. Int. 30 (2004) 135-143.

[31] M. Akyüz, Atmos. Environ. 42 (2008) 3809-3819.

[32] G. Palmiotto, G. Pieraccini, G. Moneti, P. Dolara, Chemosphere 43 (2001) 355361.

[33] J.W. Eric, C. Dalizza, L.B. George, Environ. Sci. Technol. 35 (2001) 2470-2475.

[34] M. Ratti, S. Canonica, K. McNeill, J. Bolotin, T.B. Hofstetter, Environ. Sci. Technol. 49 (2015) 12766-12773.

[35] M.W. Mahoney, W.L. Jorgensen, J. Chem. Phys. 112 (2000) 8910-8922.

[36] M.J. Shultz, Annu. Rev. Phys. Chem. 68 (2017) 13.11-13.20.

[37] V. Buch, B. Sigurd, J. Paul Devlin, U. Buck, J.K. Kazimirski, Int. Rev. Phys. Chem. 23 (2004) 375-433.

[38] N. Materer, U. Starke, A. Barbieri, M.A.V. Hove, G.A. Somorjai, G.-J. Kroes, C. Minot, J. Phys. Chem. 99 (1995) 6267-6269.

[39] Z.H. Fu, N. He, P.T. Zhou, J.X. Liu, H.B. Xie, Q. Yu, F.F. Ma, Z.Q. Fu, Z.Y. Wang, J.W. Chen, J. Phys. Chem. C 121 (2017) 15746-15755.

[40] Q. Yu, H.B. Xie, J.W. Chen, Sci. Total Environ. 571 (2016) 1105-1114.

[41] M. Bockstedte, A. Michl, M. Kolb, M. Mehlhorn, K. Morgenstern, J. Phys. Chem. C 120 (2016) 1097-1109.

[42] S.K. Ignatov, O.B. Gadzhiev, A.G. Razuvaev, A.E. Masunov, O. Schrems, J. Phys. Chem. C 118 (2014) 7398-7413.

[43] M.A. Shoaib, C.H. Choi, J. Phys. Chem. C 117 (2013) 4181-4188.

[44] I. Sumi, S. Picaud, P. Jedlovszky, J. Phys. Chem. C 121 (2017) 7782-7793.

[45] I. Sumi, S. Picaud, P. Jedlovszky, J. Mol. Liq. 245 (2017) 17-26.

[46] I. Sumi, S. Picaud, P. Jedlovszky, J. Phys. Chem. C 119 (2015) 17243-17252.

[47] M. Mezei, MMC: Monte Carlo Program for Simulation of Molecular Assemblies. URL: http://inka.mssm.edu/ mezei/mmc/.

[48] M. Mezei, Molecular Physics 67 (1989) 1207-1208.

[49] M. Mezei, Molecular Physics 40 (1980) 901-906.

[50] C. Vega, J.L. Abascal, Phys. Chem. Chem. Phys. 13 (2011) 19663-19688.

[51] J.L. Abascal, C. Vega, J Chem Phys 123 (2005) 234505.

[52] C. Vega, E. Sanz, J.L.F. Abascal, J. Chem. Phys. 122 (2005) 114507.

[53] B. Ivan, G. Alfons, O. Alla, J. Chem. Phys. 123 (2005) 044515.

[54] P. Jedlovszky, G. Hantal, K. Neurohr, S. Picaud, P.N.M. Hoang, P. von Hessberg, J.N. Crowley, J. Phys. Chem. C 112 (2008) 8976-8987.

[55] M. Darvas, J. Lasne, C. Laffon, P. Parent, S. Picaud, P. Jedlovszky, Langmuir. 28 (2012) 4198-4207.

[56] G. Hantal, P. Jedlovszky, J. Phys. Chem. C 111 (2007) 14170-14178.

[57] G. Hantal, P. Jedlovszky, P.N. Hoang, S. Picaud, Phys. Chem. Chem. Phys. 10 (2008) 6369-6380.

[58] R. Vacha, P. Jungwirth, J. Chen, K. Valsaraj, Phys. Chem. Chem. Phys. 8 (2006) 4461-4467.

[59] R. Vacha, P. Slavicek, M. Mucha, B.J. Finlayson-Pitts, P. Jungwirth, J. Phys. Chem. A 108 (2004) 11573-11579. 
[60] W.L. Jorgensen, E.R. Laird, T.B. Nguyen, J. Tirado-Rives, J. Chem. Theory Comput. 14 (1993) 206-215.

[61] L.B. Partay, P. Jedlovszky, P.N.M. Hoang, S. Picaud, M. Mezei, J. Phys. Chem. C 111 (2007) 9407-9416.

[62] K. Roos, C. Wu, W. Damm, M. Reboul, J.M. Stevenson, C. Lu, M.K. Dahlgren, S. Mondal, W. Chen, L. Wang, R. Abel, R.A. Friesner, E.D. Harder, J. Chem. Theory Comput. 15 (2019) 1863-1874.

[63] E. Harder, W. Damm, J. Maple, C. Wu, M. Reboul, J.Y. Xiang, L. Wang, D. Lupyan, M.K. Dahlgren, J.L. Knight, J.W. Kaus, D.S. Cerutti, G. Krilov, W.L. Jorgensen, R. Abel, R.A. Friesner, J. Chem. Theory Comput. 12 (2016) 281-296.

[64] M.J. Frisch, G.W. Trucks, H.B. Schlegel, G.E. Scuseria, M.A. Robb, J.R. Cheeseman, G. Scalmani, V. Barone, B. Mennucci, G.A. Petersson, H. Nakatsuji, Gaussian 09, revision A.01; Gaussian, Inc.: Wallingford, CT, 2009.

[65] B. Hess, C. Kutzner, D. van der Spoel, E. Lindahl, J. Chem. Theory Comput. 4 (2008) 435-447.

[66] R. Sander, http://www.henrys-law.org (1999).

[67] R. Sander, Atmos. Chem. Phys. 15 (2015) 4399-4981.

[68] I. Langmuir, J. Am. Chem. Soc. 38 (1916) 2221-2295.

[69] P. Loganathan, W.G. Shim, D.P. Sounthararajah, M. Kalaruban, T. Nur, S. Vigneswaran, Environ. Sci. Pollut. Res. Int. 25 (2018) 16664-16675.

[70] B. Koubaissy, G. Joly, I. Batonneau-Gener, P. Magnoux, Ind. Eng. Chem. Res. 50 (2011) 5705-5713.

[71] I. Sumi, B. Fábián, S. Picaud, P. Jedlovszky, J. Phys. Chem. C 120 (2016) 1738617399.

[72] M. Szőri, P. Jedlovszky, J. Phys. Chem. C 118 (2014) 3599-3609.

[73] P. Marco, C. Gianni, R. Roberto, S. Vincenzo, J. Chem. Phys. 119 (2003) 6655.

[74] J.A. da Silva, F.G. Moreira, V.M. Dos Santos, R.L. Longo, Phys. Chem. Chem. Phys. 13 (2011) 593-603. 


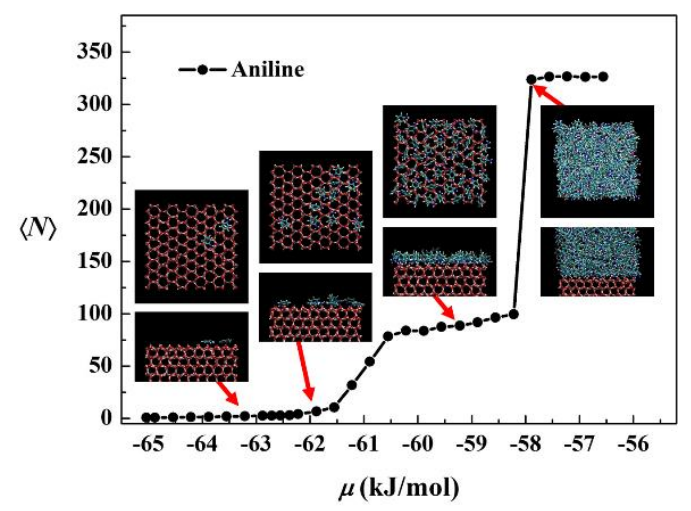

Graphical abstract 


\section{Highlights:}

- The modified aniline force field is better than original Jorgensen's OPLS-AA.

- Under very low surface coverage, the adsorption isotherm apparently follows Langmuir type adsorption isotherm.

- Most anilines are almost parallel to the ice surface and form two $\mathrm{N}-\mathrm{H} \bullet \bullet \mathrm{O}$ hydrogen bonds.

- The adsorption energy from GCMC simulation is well consistent with that from our validating quantum chemistry calculation. 